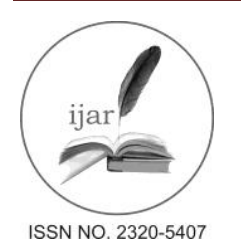

Journal homepage: http://www.journalijar.com

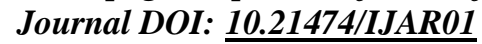

INTERNATIONAL JOURNAL

OF ADVANCED RESEARCH

RESEARCH ARTICLE

\title{
PATTERN OF LYMPHADENITIS AS DETECTED BY FNAC IN A HOSPITAL BASED STUDY ON THE WEST LUCKNOW POPULATION.
}

\author{
Nishi Tandon, Neema Tiwari, Namrata Mishra, Nirupama Lal, *A.N Srivatava. \\ Dept. Of Pathology, Era's Lucknow Medical College and Hospital,Lucknow, UP.
}

\section{Manuscript Info}

Manuscript History:

Received: 14 April 2016

Final Accepted: 18 May 2016

Published Online: June 2016

Key words:

Lymphadenopathy, FNAC, hospital, based

*Corresponding Author

A.N Srivatava.

\begin{abstract}
Background: Chronic non specific lymphadenitis and reactive lymphadenitis are two problems on rise in the current Indian population, both in adult as well as pediatric age group. The biggest problem being faced by the cytologists in the diagnosis of such disorders due to widespread chronicity of the diseases affecting the lympnode as well as loss of patient compliance where early detection investigation and treatment of the disease is concerned. The incomplete or over enthusiastic antibiotic therapy which leads to incomplete resolution of the disease also adds to the confusion. The present study aimed at delineating the different types of lymph node lesions diagnosed by FNAC and the frequency of different benign and malignant lesions diagnosed.

Material and methods: We reviewed 213 cases of lymphadenopathy from May 2014 to June 2015. The cytomorphological features seen in the aspirate were critically analysed and correlated with their aetiology.

Results: In our study of 213 cases of lymphadenopathy analyzed in retrospect, the age groups ranged from 3-65 yrs, with $73 \%$ cases being of adults. There was a slight male preponderance with $56 \%$ of the samples being from males. The first most common cause of lymphadenopathy visiting our hospital came out to be granulomatous lesions[41.7\%], caseating [65.2\%] more that non caseating granulomas[34.8\%].Second most common cause was chronic non-specific lymphadenitis [32.4\%], while the third group being reactive lymphadenitis-a cause that does not warrant treatment was approximately, $23.9 \%$ of the total cases. Metastatic causes accounted for only 3 cases [1.5\%] in our study-number being too small to draw any conclusion regarding their incidence. The filarial lymphadenitis was just $0.5 \%$ of the total diagnosis[1 case]. The most common site for FNAC was the cervical region, 165 out of 213 cases. The most common lesion occurring in the older age group is the $20-40$ years while the reactive lesions had a more common predilection for patients less than 20 years of age.

Conclusions: Tuberculosis is still the dominant infection in the rural population specially in the adult age group while the paediatric age group presented with mainly chronic non specific pathology hence tuberculosis needs a vigilant detection, management and treatment protocol.
\end{abstract}

\section{Introduction:-}

Lymphadenopathy is one of the most common clinical complains of patients, presenting to the outdoor clinics in most hospitals. The etiology of lymphadenopathy varies from an inflammatory process to a malignant condition [1]. Enlarged palpable cervical lymph nodes are common and worrying presentation in adults as well as in children. Cervical lymph nodes are involved most often in all types of lymphadenopathy [2]. A lymph node is said to be abnormal or pathologic if it is $>1 \mathrm{~cm}$ in size in adult population. In the pediatric population, $>2 \mathrm{~cm}$ is considered 
abnormal. The cause of lymphadenopathy may range from reactive to tubercular to malignant. Types of adenopathy

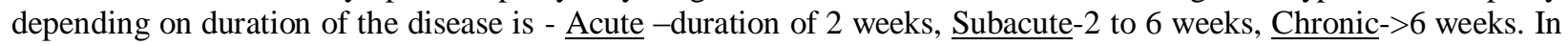
tuberculous lymphadenitis, it not only used for the cytological diagnosis but also used for other ancillary testing such as Ziehl- Neelsen staining and AFB Culture[3]

Fine needle aspiration cytology (FNAC) of lymph node has become an integral part of the initial diagnosis and management of patients with lymphadenopathy. Due to its early availability of results, simplicity, and, minimal trauma with less complication, FNAC is considered the first line of diagnosis in patients suffering from lymphadenopathy. [2]. FNAC has also been proved to be more useful as compared to biopsies ,especially in countries like ours, with limited financial and health care resources [3].

It almost offers an accurate diagnosis for reactive lymphoid hyperplasia, infectious disease, granulomatous lymphadenitis, and metastatic malignancy. Hence FNAC can lead to rapid diagnosis and prompt therapy negating the need of long drawn biopsy procedures and the delay caused in histopathology reports. [4].

Even the diagnosis of metastatic tumor to the lymph node on cytological smear, is crucial and highly reliable. This would be the sole indication for searching the primary tumor, especially in cases of occult carcinoma [5]. Most of metastatic carcinoma can be identified by their cytomorphological characteristics alone. However biopsy still remains important in accurate and definite diagnosis of a tumor [6]. Cytoimmunochemistry is opening up newer doors for diagnostic cytopathology specially in the field of oncology [7]. Some authors state that cytology is a more readily accepted methodology for the evaluation of deep seated lymph nodes where surgical resection is not possible.[8]Although the reliability of FNAC of cervical lymph node has been shown in some studies but there are also some reports in contrary $[9,10]$. The present study aimed at delineating the different types of lymph node lesions diagnosed by FNAC and the frequency of different benign and malignant lesions diagnosed.

\section{Material and methods:-}

The aim of the present study is to assess tubercular/ non-tubercular lymphadenitis, as our set up caters to mainly the rural population where we anticipate poverty driven infections besides tuberculosis. 213 consecutive cases of lymphadenopathy from May 2014 to July 2015 received in the department of Pathology, Eras Lucknow Medical College and Hospital was analysed in retrospect. All the patients having palpable lymph node were included. All demographic details, clinical history and physical findings were noted. The cases were analysed under the subheadings of granulomatous [caseating+ non caseating],chronic non specific, parasitic[filarial] and metastasis in lymphnode. The results noted and analysed on the basis of age of distribution. Sex and percentage of cases suffering from lymphadenopathy in each category. The slides were stained by Haematoxylin and Eosin[HnE] and AFB[ZN staining where indicated.

\section{Results:-}

In our study of 213 cases of lymphadenopathy analyzed in retrospect, the age groups ranged from 3-65 yrs, with $73 \%$ cases being of adults.[Fig-1] There was a slight male preponderance with $56 \%$ of the samples being from males.[Fig-2] The first most common cause of lymphadenopathy visiting our hospital came out to be granulomatous lesions[41.7\%], caseating [65.2\%] more that non caseating granulomas[34.8\%].

Second most common cause was chronic non-specific lymphadenitis [32.4\%], while the third group being reactive lymphadenitis-a cause that does not warrant treatment was approximately,23.9\% of the total cases. Metastatic causes accounted for only 3 cases [1.5\%] in our study-number being too small to draw any conclusion regarding their incidence. The filarial lymphadenitis was just $0.5 \%$ of the total diagnosis[1 case] which could be attributed to decreased frequency of occurrence of the parasite in this area or early treatment rates with prompt diagnosis on peripheral blood smears[Table-1]. The most common site for FNAC was the cervical region, 165 out of 213 cases[Table-2]. The most common lesion occurring in the older age group is the 20-40 years while the reactive lesions had a more common predilection for patients less than 20 years of age [Table-3].Images of various patterns of the common lymphadenitis have been discussed further on.[FIG. A-T]

\section{Discussion:-}

In India, tuberculous lymphadenopathy is one of the most common type of lymphadenopathy encountered [25].However tuberculosis is not the only disease entity diagnosed in fact most of the patients below age of 20 years are diagnosed as reactive lymphadenitis and cases with long standing lymphadenopathy may give a picture of 
chronic non specific lymphadenitis. The cytological criteria for the diagnosis of possible tubercular lymphadenitis is epithelioid cell granulomas with or without multinucleated giant cells and presence or absence of caseating necrosis [4].It should be kept in mind that lymphadenopathy is the most common presentation of extra pulmonary tuberculosis [6,7]. Pediatric cervical lymphadenopathy is a challenging medical condition for the patient, the parent, and the physician. 38-45\% of normal healthy children [8] and 90\% of children aged 4-8 years [9] will have cervical lymphadenopathy.

In our study it was clearly seen that caseating granulomatous lesions had the highest frequency of diagnosis. These findings corroborate with some other study findings like in a study done by [10] where they saw that among the four cytological patterns on FNAC, maximum cases demonstrated caseous necrotic material with degenerated inflammatory cells. Another study categorized lesions depending upon cytomorphological features, three patterns were found in tuberculous lymphadenitis:

(1) Granulomatous lymphadenitis,

(2) Caseating necrotizing lymphadenitis,

(3) Acute inflammation with granulomas.

The cytomorphological features observed were granulomatous lymphadenitis in 57.8\% (52/90), caseating necrotizing lymphadenitis in 31.1\% (28/90), and acute inflammation with granulomas in 11.1\% (10/90) cases [11].In a study [12] they concluded that FNAC is simple, quick, minimally invasive, and inexpensive technique to diagnose cervical lymphadenopathy. They also saw that FNAC can differentiate a neoplastic from a non-neoplastic process and therefore influence patient management preventing patient from being subjected to unnecessary surgery. Another study [13] showed that in 1926 cases of lymphadenopathy , 1136 cases (59 \%) were granulomatous lymphadenitis , 500 cases ( $26 \%$ ) were Non-specific lymphadenitis , 232 cases (12\%) of lympho-proliferative disorders (Hodgkin's and Non-Hodgkin's disease) 58 cases (03\%) metastases from primary site. Hence they concluded that Fine Needle Aspiration Cytology is a simple, safe, rapid, cost effective and reasonably accurate method of establishing the diagnosis of lymphadenopathy. Fine needle aspiration cytology (FNAC) has assumed an important role in the evaluation of peripheral adenopathy as a possible noninvasive alternative to excision biopsy [14] Overall accuracy of FNAC in comparison with the histopathological study is very high and may obviate the need of excision biopsy when the findings are compatible with the clinical diagnosis. The high accuracy rate of aspiration cytology of lymph nodes makes it in important tool of investigation in daily practice.

In one of the studies based on the cytomorphology of lymph node lesions the overall diagnostic accuracy of FNAC was $82.2 \%$. Many other authors in similar studies have reported an accuracy rate of $85 \%$ to $94.4 \%$ [15,16,17]. In another study the authors found a much higher accuracy rate (97.6\%) of FNAC in diagnosis lymphadenopathies[17].The diagnostic accuracy of reactive lymphoid hyperplasia in the one study was seen as 85\%.Al-Mulhim et al. reported 100\% diagnostic accuracy in reactive lesions in lymph node by FNAC. [18]

In another study, the diagnostic accuracy of the chronic necrotizing lymphadenitis was 83.3 Some authors report 93\% diagnostic accuracy for such cases.[19] In the some studies, the diagnostic accuracy of chronic granulomatous lymphadenitis has been seen to be $70 \%$.[20,21]

Hence it is advisable to remember that tissue biopsy is gold standard in diagnosing lymphadenopathy specially if the clinical, radiological, or laboratory data are not consistent with granulomatous disease, to exclude a granulomatous response to a malignant neoplasm within the node. 


\section{Patterns of lymphadenitis in cytology:-}

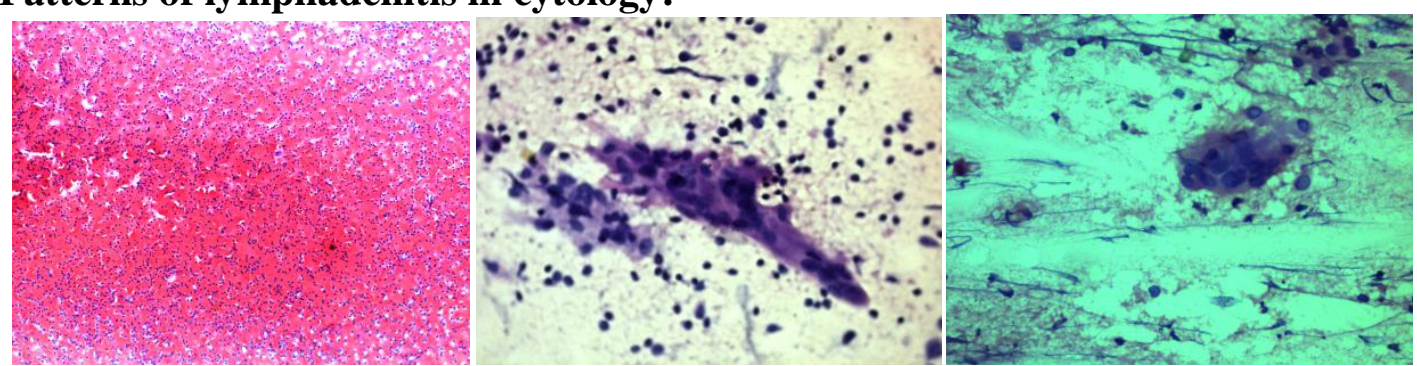

Figa-reactive lymphadenitis;fig.b\&c-epitheloid cells forming granulomas

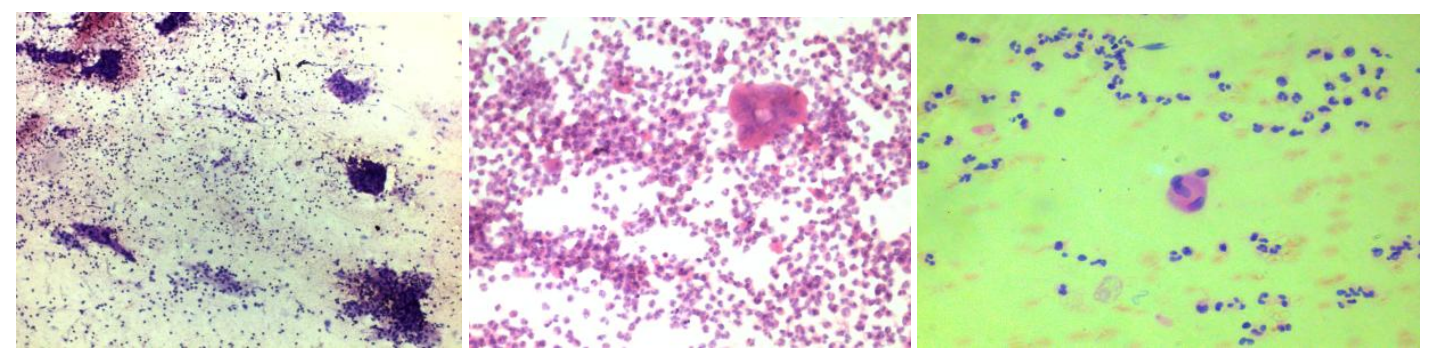

Figd-10x showing granulomas on fnac;fige\&f giant cells in tubercular abscess

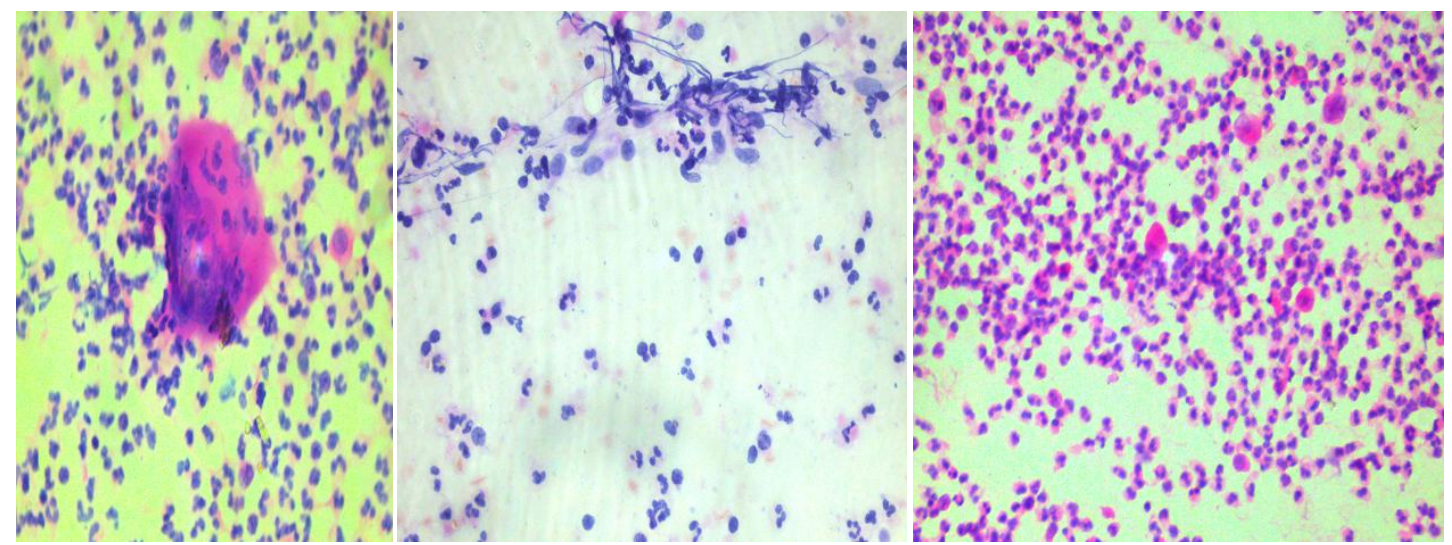

Fig-g-40x of giant cell;fig-h epithelioid cell granuloma;fig-i tubercular abscess with histiocytes

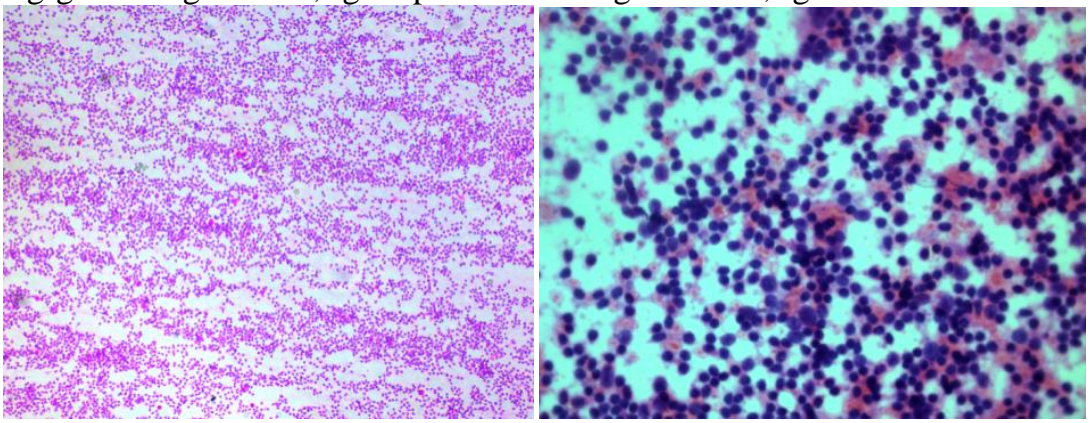

Fig j-reactive lymphnode 10x;fig-k-reactive lymphnode 40x 


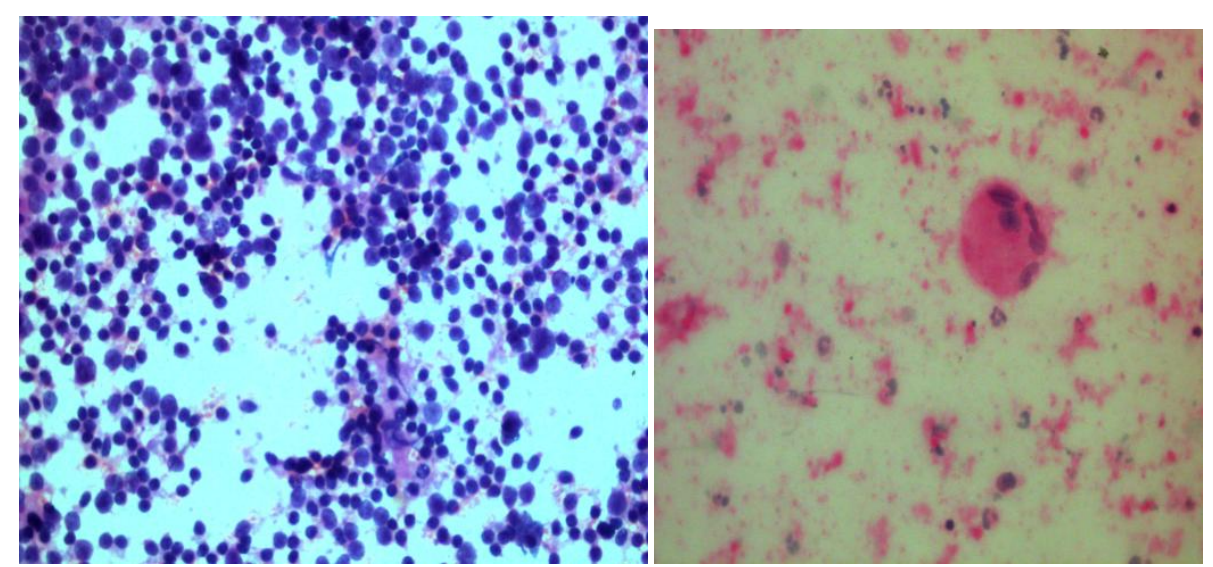

Fig-l reactive lymph node[40x]; fig-m giant cell in $\mathrm{tb}[40 \mathrm{x}]$

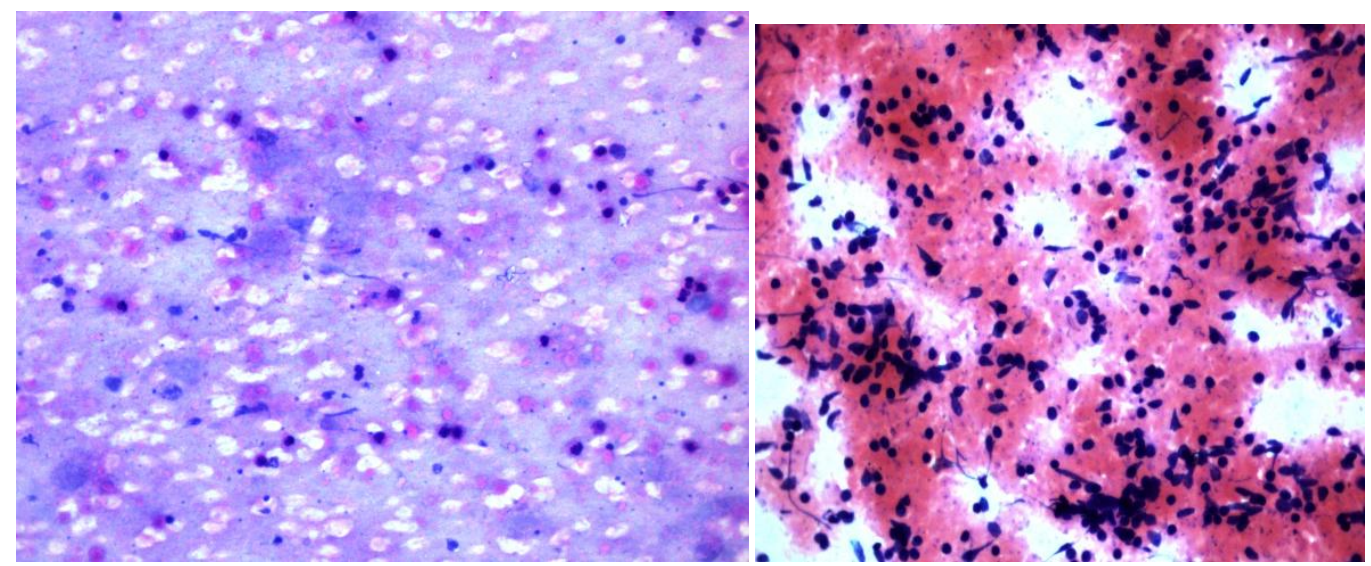

Fig- $\mathrm{n}$ suppurative pathology in lymph node ?tb[40x] ; fig-o- chronic lymphadenitis[40x]

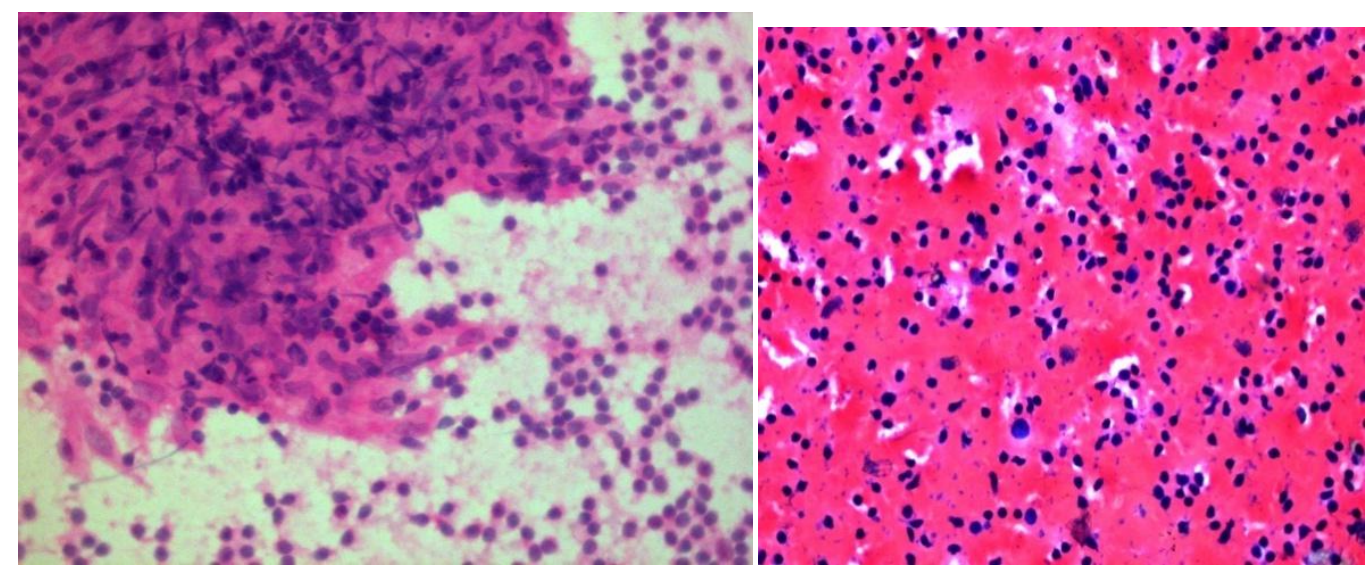

Fig p- well formed tb granuloma[40x]; fig-q-chronic lymphadenitis[40x] 


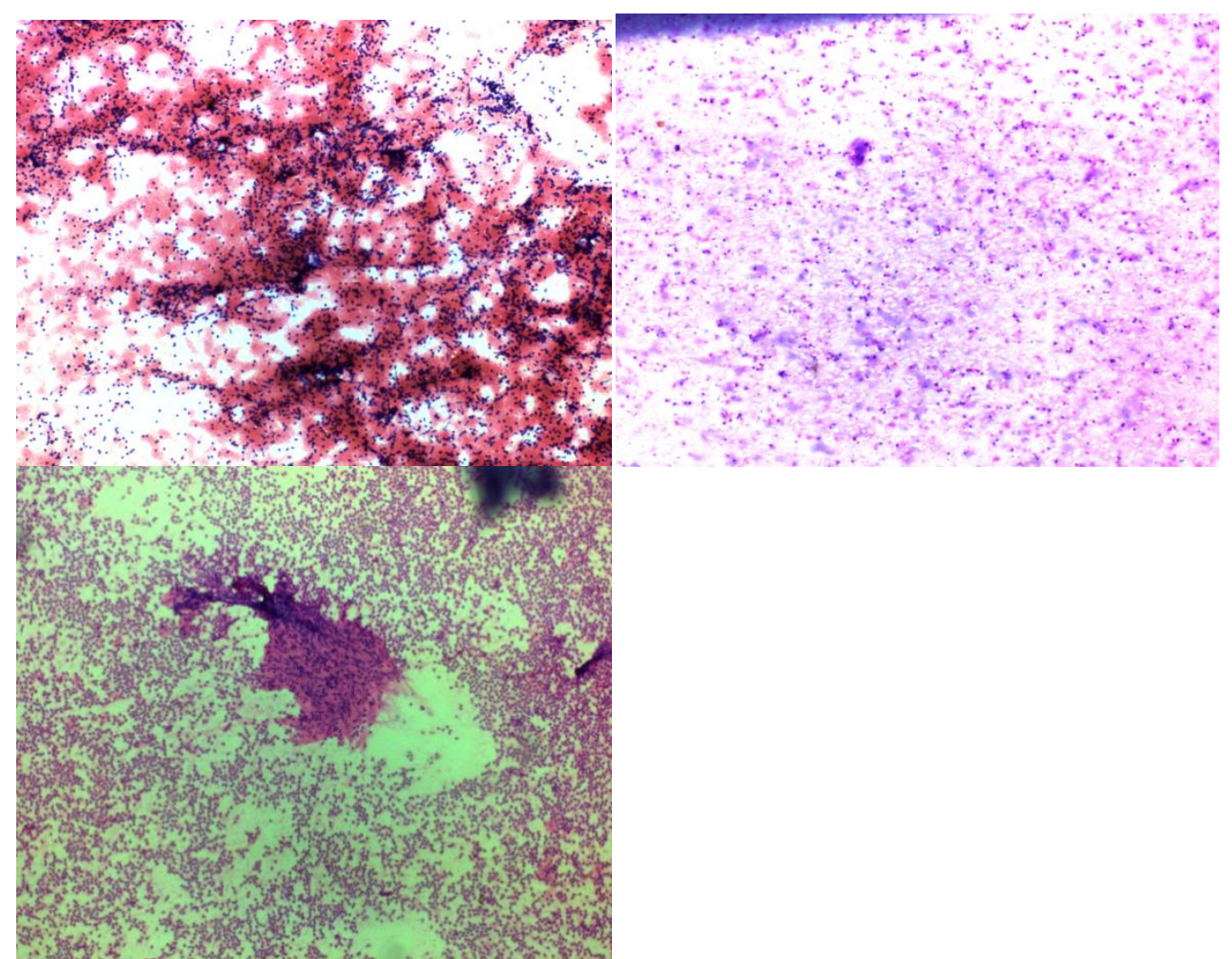

Fig-r-chrnic lymhadenitis[10x], fig-s- tubercular abscess[10x]; fig t- tb granuloma[10x]

\section{Charts and figures:-}

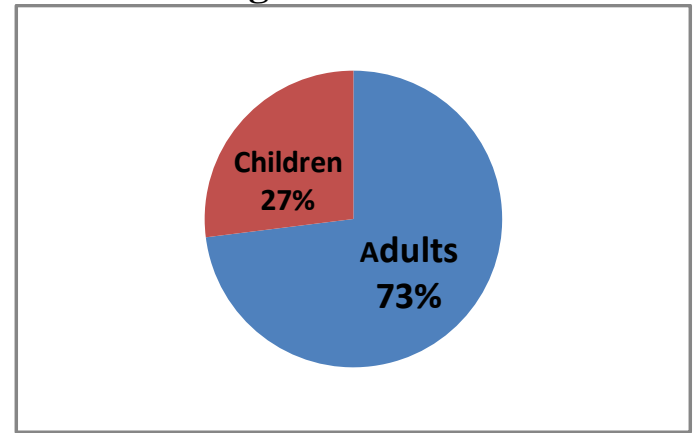

Figure 1-Percentage of children and adults

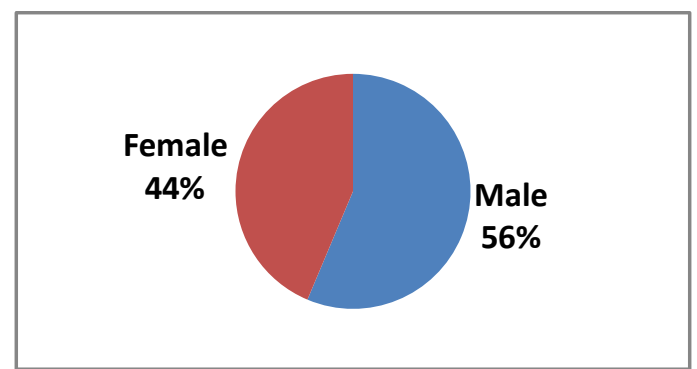

Figure 2-the distribution of lymphadenopathy in males and females 
Table 1-distribution of different patterns of

\begin{tabular}{|l|l|l|}
\hline Cytological diagnosis & no. of cases & Percentage \\
\hline 1]granulomatous lymphadenitis & & $41.7 \%$ \\
\hline A) with caseation & 58 & $65.2 \%$ \\
\hline B) without caseation & 31 & $34.8 \%$ \\
\hline 2]reactive lymphadenits & 51 & $23.9 \%$ \\
\hline 3]chronic non-specific lymphadenitis & 69 & $32.4 \%$ \\
\hline 4]metastaic lymphadenitis & 3 & $1.5 \%$ \\
\hline 5]filarial lymphadenitis & 1 & $0.5 \%$ \\
\hline
\end{tabular}

lymphadenitis

Table 2-distribution as per site of fnac

\begin{tabular}{|l|l|}
\hline Site & Number \\
\hline Cervical & 165 \\
Submental & 06 \\
Submandibular & 06 \\
Supraclavicular & 01 \\
Inguinal & 20 \\
Arm & 15 \\
Occipital & 00 \\
\hline Total & 213 \\
\hline
\end{tabular}

Table 3-distribution as per age

\begin{tabular}{|c|c|c|c|c|c|}
\hline Type & & 0-20yrs & 21-40yrs & 41-60yrs & $>60 \mathrm{yrs}$ \\
\hline $\begin{array}{l}\text { Casesating } \\
\text { garnuloma }\end{array}$ & $\begin{array}{l}\mathrm{M} \\
\mathrm{F}\end{array}$ & $\begin{array}{l}2 \\
6\end{array}$ & $\begin{array}{l}13 \\
10\end{array}$ & $\begin{array}{l}10 \\
10\end{array}$ & $\begin{array}{l}5 \\
10 \\
\end{array}$ \\
\hline $\begin{array}{l}\text { Non casesating } \\
\text { garnuloma }\end{array}$ & $\begin{array}{l}\mathrm{M} \\
\mathrm{F} \\
\end{array}$ & $\begin{array}{l}5 \\
6 \\
\end{array}$ & $\begin{array}{l}8 \\
10 \\
\end{array}$ & $\begin{array}{l}2 \\
4 \\
\end{array}$ & $\begin{array}{l}1 \\
2 \\
\end{array}$ \\
\hline Reactive & $\begin{array}{l}\mathrm{M} \\
\mathrm{F}\end{array}$ & $\begin{array}{l}20 \\
5\end{array}$ & $\begin{array}{l}7 \\
5\end{array}$ & $\begin{array}{l}7 \\
2\end{array}$ & $\begin{array}{l}1 \\
1\end{array}$ \\
\hline $\begin{array}{l}\text { Chronic non } \\
\text { specific } \\
\text { inflammation }\end{array}$ & $\begin{array}{l}\mathrm{M} \\
\mathrm{F}\end{array}$ & $\begin{array}{l}5 \\
5\end{array}$ & $\begin{array}{l}22 \\
10\end{array}$ & $\begin{array}{l}2 \\
3\end{array}$ & $\begin{array}{l}8 \\
2\end{array}$ \\
\hline Filaria & $\begin{array}{l}\mathrm{M} \\
\mathrm{F}\end{array}$ & $\begin{array}{l}0 \\
0\end{array}$ & $\begin{array}{l}1 \\
0\end{array}$ & $\begin{array}{l}0 \\
0\end{array}$ & $\begin{array}{l}0 \\
0\end{array}$ \\
\hline Metastasis & $\begin{array}{l}\mathrm{M} \\
\mathrm{F}\end{array}$ & $\begin{array}{l}0 \\
0\end{array}$ & $\begin{array}{l}0 \\
0\end{array}$ & $\begin{array}{l}1 \\
0\end{array}$ & $\begin{array}{l}0 \\
2\end{array}$ \\
\hline
\end{tabular}

\section{Conclusion:-}

Despite its limitations and pitfalls, FNAC appears as a good first line method for investigating the cases of cervical lymphadenopathy Tuberculosis is still the dominant infection in the rural population, especially in the adult age group, while the paediatric age group presented mainly with chronic non-specific pathology. Hence tuberculosis needs a vigilant detection, management and treatment protocol. The high incidence of tuberculosis in our set up may be due to the fact that our hospital caters to a large population of low socioeconomic strata.

\section{Refrences:-}

1. Steel BL, Schwartz MR, Ramzy I. Fine needle aspiration biopsy in the diagnosis of lymphadenopathy in 1103 patients. Role, limitations and analysis of diagnostic pitfalls. Acta Cytol 1995;39:76-81

2. Ustun M, Risberg B, Davidson B, Berner A. Cystic Change in metastatic lymph Nodes: A common diagnostic pitfall in Fine-NeedleAspiration Cytology. Diagn Cytopathol 2002;27:387-92.

3. Kusum V, Mandal S, Kapila K. Cystic change in lymph nodes withmetastatic squamous cell carcinoma. Acta Cytol 1995;39:478-80.

4. Monchik JM, De Petris G, De Crea C. Occult papillary carcinoma ofthe thyroid presenting as a cervical cyst. Surgery 2000;129:429-32. 
5. Thomas Jo, Adeyi D, Amanguno H. Fine-needle aspiration in themanagement of peripheral lymphadenopathy in a developing country.Diagn Cytopathol 1999;21:159-62.

6. Schafernak KT, Kluskens LF, Ariga R, Reddy VB, Gattuso P. Fine needle aspiration of superficial and deeply seated lymph nodes on patients with and without a history of malignancy: review of 439 cases. Diagn Cytopathol 2003;29:315-9.

7. Nasuti JF, Mehrotra R, Gupta PK. Diagnostic value of fine-needleaspiration in supraclavicular lymphadenopathy: a study of 106patients and review of literature. Diagn Cytopathol 2001;25:351-5.

8. El Hag IA, Chiedozi LC, al Reyees FA, Kollur SM. Fine needle aspiration cytology of head and neck masses. Seven years' experience in a secondary care hospital. Acta Cytol. 2003;47:387-92.

9. Fulciniti F, Califano L, Zupi A, Vetrani A: Accuracy of Fine needle aspiration biopsy in head and neck tumours. J Oral Maxillofac Surg 1997;55:1094-7

10. Bagwan IN, Kane SV, Chinoy RF. Cytologic Evaluation of the Enlarged Neck Node: FNAC Utility in Metastatic Neck Disease. The Internet Journal of Pathology. 2007; 6(2).

11. Appling D and Miller RH. Mycobacterial cervical lymphadenopathy 1981 update. Laryngoscope 1981;91:1259-66.

12. Hooper AA. Tuberculous peripheral lymphadenitis. Br J Surg 1972;59:353-9

13. Krishnaswamy $\mathrm{H}$, Koshi $\mathrm{G}$ and Kulkarni KG, et al. Tuberculous lymphadenitis in South India-a histopathological and bacteriological study. Tubercle 1972;53:215-20

14. Gupta AK, Nayar M and Chandra M. Critical appraisal of fine needle aspiration cytology in tuberculous lymphadenitis. Acta Cytol 1992;36:391-4

15. Bezabih M and Mariam DW. Determination of aetiology of superficial enlarged lymph nodes using fine needle aspiration cytology. East Afr Med J. 2003 Nov;80(11):559-63

16. Mohammed Hussain and Nadeem Rizvi. Clinical and morphological evaluation of Tuberculous Peripheral Lymphadenopathy.J Coll Physicians Surg Pak Dec 2003;13(12):694-6

17. Tariq Butt, Rifat Nadeem Ahmad, Syed Yousaf Kazmi, Raja Kamran Afzal, Abid Mahmood. An update on the diagnosis of Tuberculosis.J Coll Physicians Surg Pak Dec2003;13(12):728-34.

18. Ajmal Farooq, Imran Ameen. Comparison of FNAC vs Excision Biopsy for suspected Tuberculous Cervical Lymphadenopathy. Ann King Edward Med Coll Sep 2003;9(3):216-8.

19. Dandapat MC, Panda BK, Patra AK, et al. Diagnosis of tubercular lymphadenitis by fineneedle aspiration cytology. Indian Journal of Tuberculosis 1987;34:139-42.

20. Kline TS. Lymph nodes and superficial masses. In: Lotz JE, ed. Handbook of fine needle aspiration cytology. St Louis: Mosby, 1981: 23-64.

21. Finfer M, Perchick A and Barstein DE. Fine needle aspiration biopsy diagnosis oftuberculous lymphadenitis in patients with and without the acquired immune deficiency syndrome. Acta Cytol 1991;35:325-32 